\title{
"Como vai você?": projeto de aplicativo para o Centro De Valorização Da Vida
}

\section{"How are you?": application design for the Centro de Valorização da Vida}

\author{
Hellen de Aguiar Rodrigues ${ }^{[1]}$, \\ Cilene Estol Cardoso (orientadora) ${ }^{[2]}$
}

\begin{abstract}
Resumo: Este artigo é parte integrante de um Trabalho de Conclusão de Curso intitulado: "Como vai você?": Projeto de Aplicativo para o Centro de Valorização da Vida", defendido e aprovado em julho de 2019 no Centro de Artes. O trabalho teve por intuito projetar um aplicativo para o Centro de Valorização da Vida, CVV, uma associação civil sem fins lucrativos que oferece apoio emocional e prevenção ao suicídio a todos que necessitarem. Para isto, buscou-se um referencial teórico onde se contextualizou saúde mental e depressão. Além disto, procurou-se entender sobre as tecnologias de aplicativos móveis, como a mHealth, e aplicativos voltados para saúde mental. O projeto prático teve como base as etapas metodológicas de Jesse James Garrett (2011), voltado à experiência do usuário.
\end{abstract}

Palavras-chave: Centro de Valorização da Vida. Saúde Mental. Depressão. Aplicativos móveis. mHealth.

\begin{abstract}
This paper presents the course completion work for a bachelor's degree in Digital Design at the Univesidade Federal de Pelotas, entitled "How are you?": Application Design for the Centro de Valorização da Vida, defended and approved in July 2019 at the Centro de Artes. The work aimed to design an application for the Centro de VaIorização da Vida, CVV, a non-profit civil association that offers emotional support and suicide prevention to all who need it. For this, we sought a theoretical framework that contextualized mental health and depression. In addition, we sought to understand mobile application technologies such as mHealth and mental health applications. The
\end{abstract}

[1] Graduada em Design Digital, UFPEL. hellsrodrigues@gmail.com

[2] Doutora em Design, UFRGS. cilene.estol@ufpel.edu.br 
practical project was based on the methodological steps of Jesse James Garrett (2011), focused on the user experience.

Keywords: Centro de Valorização da Vida. Mental Health. Depression. Mobile Applications. mHealth.

\section{INTRODUÇÃO}

O seguinte artigo apresenta o trabalho de conclusão de curso em Design Digital na Universidade Federal de Pelotas, intitulado "Como vai você?': Projeto de Aplicativo para o Centro de Valorização da Vida". A presença dos dispositivos móveis tem se tornado mais frequentes na vida cotidiana das pessoas, e seu uso tem cada vez mais se expandido, onde tornou-se uma espécie de ampliação da casa de seus usuários ou até mesmo de seus próprios corpos (SABOIA; VARGAS; VIVA, 2013). Segundo o PRODEST (2016), os aplicativos para dispositivos móveis, softwares desenvolvidos para serem instalados em dispositivos móveis, como celulares smartphones e tablets, pertencem cada vez mais à rotina das pessoas, proporcionando as mais diversas utilidades que são práticas, como chamar um táxi, encomendar uma refeição, acessar a internet, escutar músicas, entre outras. A sua utilização tornou-se cada vez mais ampla, pois existem aplicativos que podem inclusive ajudar a pessoa a controlar suas finanças, buscar imóveis para aluguel, organizar uma viagem, até mesmo fazer terapias online, ou agendar consultas médicas. Estes aplicativos voltados para saúde fazem parte da mHealth ou Mobile Health.

Ao longo dos anos, a sociedade vem sofrendo cada vez mais com um problema de saúde pública: A depressão. Segundo dados da Organização Mundial de Saúde (2018), estima-se que mais de 300 milhões de pessoas sofram com a doença. Ela pode causar, conforme a organização na pior das hipóteses, o suicídio. Cerca de 800 mil pessoas morrem por ano por conta do suicídio, sendo a segunda principal causa de morte entre pessoas de 15 a 29 anos (OMS, 2018). Apesar da existência de tratamentos efetivos conhecidos para o tratamento da depressão, menos da metade das pessoas 
afetadas no mundo todo consegue receber estes tratamentos. As dificuldades na busca para o tratamento, incluem falta de recursos, falta de profissionais treinados, e o preconceito associado à saúde mental que ainda é bastante recorrente (OMS, 2018). Tendo em vista estas informações, identificou-se o seguinte problema: Como projetar um aplicativo que auxilia pessoas que sofrem com a depressão?

Algumas instituições, conscientes das dificuldades e dos estigmas sociais que sofrem pessoas que tem problemas com sua saúde mental, oferecem de forma voluntária, um auxílio para a superação deste problema. Uma dessas instituições é o Centro de Valorização da Vida, o CVV, uma associação civil que oferece serviço voluntário e gratuito de apoio emocional e prevenção do suicídio para todas as pessoas que buscam e necessitam conversar, sob total sigilo e anonimato, através de telefone, online ou pessoalmente.

Diante disso, optou-se por objetivo principal da pesquisa projetar um aplicativo para o Centro de Valorização da Vida, tendo em vista que o mesmo só possui um website. Para este fim, buscou-se primeiramente um referencial teórico onde contextualiza-se a saúde mental e depressão, e também a tecnologia, abordando temas como dispositivos e aplicativos móveis, além de aplicativos voltados especificamente para saúde mental. Em um segundo momento, apresenta-se o Centro de Valorização da vida, onde aborda sua história, seus serviços, e como funciona o seu website . Em seguida, parte-se para o projeto prático que teve como base as etapas metodológicas de Jesse James Garrett (2011), voltado para a experiência do usuário.

\section{METODOLOGIA}

Quando se projeta um aplicativo, deve-se levar em conta a experiência que o usuário terá ao utiliza-lo, principalmente quando essa experiência lida com os sentimentos do mesmo. Tendo em vista essa problemática, para o desenvolvimento prático do projeto, foi empregada a metodologia projetual de 
Jesse James Garrett (2011) que auxilia na criação de projetos com base na experiência do usuário, desde a sua concepção, sendo a parte mais abstrata do projeto, até elaboração da sua parte visual, a mais concreta. Para facilitar esse processo, divide-se a experiência em cinco planos, sendo eles: plano da estratégia, plano de escopo, plano de estrutura, plano de esqueleto, e plano de superfície.

\section{PLANO DE ESTRATÉGIA}

O trabalho prático inicia-se, com base nas etapas metodológicas de Garrett (2011), pelo plano de estratégia. É a etapa mais abstrata do projeto, onde determina-se os objetivos do mesmo e compreende-se as necessidades dos usuários. Também é a etapa onde observa-se as características de seus usuários, tratadas neste projeto através de personas, e o levantamento de dados, através de um questionário online.

Com intuito de levantar dados para apurar e apontar os potenciais usuários do aplicativo, optou-se para a realização de um questionário, o qual foi realizado online através de um formulário disponibilizado pelo Google Drive. Neste questionário foram realizadas 15 perguntas, sendo algumas objetivas e obrigatórias, e outras discursivas e opcionais. No total, foram obtidas 104 respostas, com usuários que variaram de 15 a mais de 25 anos, sendo a maior parte de 19 a 25. Uma das questões levantadas foi se os participantes já haviam pensado em suicídio (Fig. 1), sendo 46,2\% respondendo que sim, e $25 \%$ que já pensou em desistir de viver mas não através do suicídio.

\section{Você já pensou em suicídio?}

104 respostas

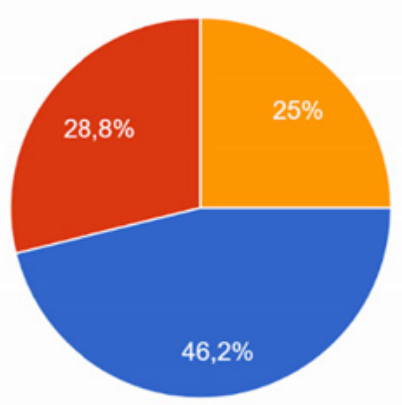

Figura 1: Dados da pergunta "Você já pensou em suicídio?" Fonte: Google Forms adaptado pela autora. 
Em seguida, foram elaboradas três personas, que conforme Garrett (2011), são personagens hipotéticos, onde a construção tem como objetivo retratar as necessidades de um variado conjunto de usuários reais. Para o auxílio desta construção, usou-se como referência a análise das respostas discursivas do questionário realizado, procurando manter uma caracterização mais real dos supostos usuários do aplicativo. A partir dessa construção de personas, deu-se por objetivo do projeto prático, o oferecimento de um auxílio rápido para as pessoas que precisam de um apoio emocional, focando também na prevenção ao suicídio e na autoajuda, com as distribuições de conteúdo. Enfatizou-se nessa etapa que a proposta do projeto não seria oferecer uma terapia online gratuita, visto que seriam voluntários que atenderiam no aplicativo, não profissionais de psicologia. Os usuários que persistirem os sintomas não deverão descartar a possibilidade de um auxílio de um profissional posteriormente.

Foi realizada também na etapa de estratégia, uma análise de semelhantes através do benchmarking. Para o projeto foram analisados quatro serviços diferentes, todos relacionados com saúde mental, sendo eles os aplicativos 7 Cups, Cíngulo, Day.lio e a inteligência artificial da empresa Eurekka. Para a análise, foi levado em conta os seus serviços, os seus pontos fortes e fracos, e também as suas principais funcionalidades.

\section{PLANO DE ESCOPO}

O plano de escopo, onde de acordo com Garrett (2011), a estratégia se torna escopo quando o projetista transforma as necessidades do usuário e os objetivos do projeto em requisitos específicos para o conteúdo e a funcionalidade que o aplicativo oferecerá para os seus usuários. Para contribuir na composição dos requisitos, foram pensados em cenários que buscam entender como o usuário poderia utilizar o aplicativo. Foram pensados três cenários que buscam entender como o usuário poderia utilizar o aplicativo, sendo o cenário 1, a busca e apoio emocional através do chat; o cenário 2, busca por auto ajuda, e o cenário 3, prevenção ao suicídio. 

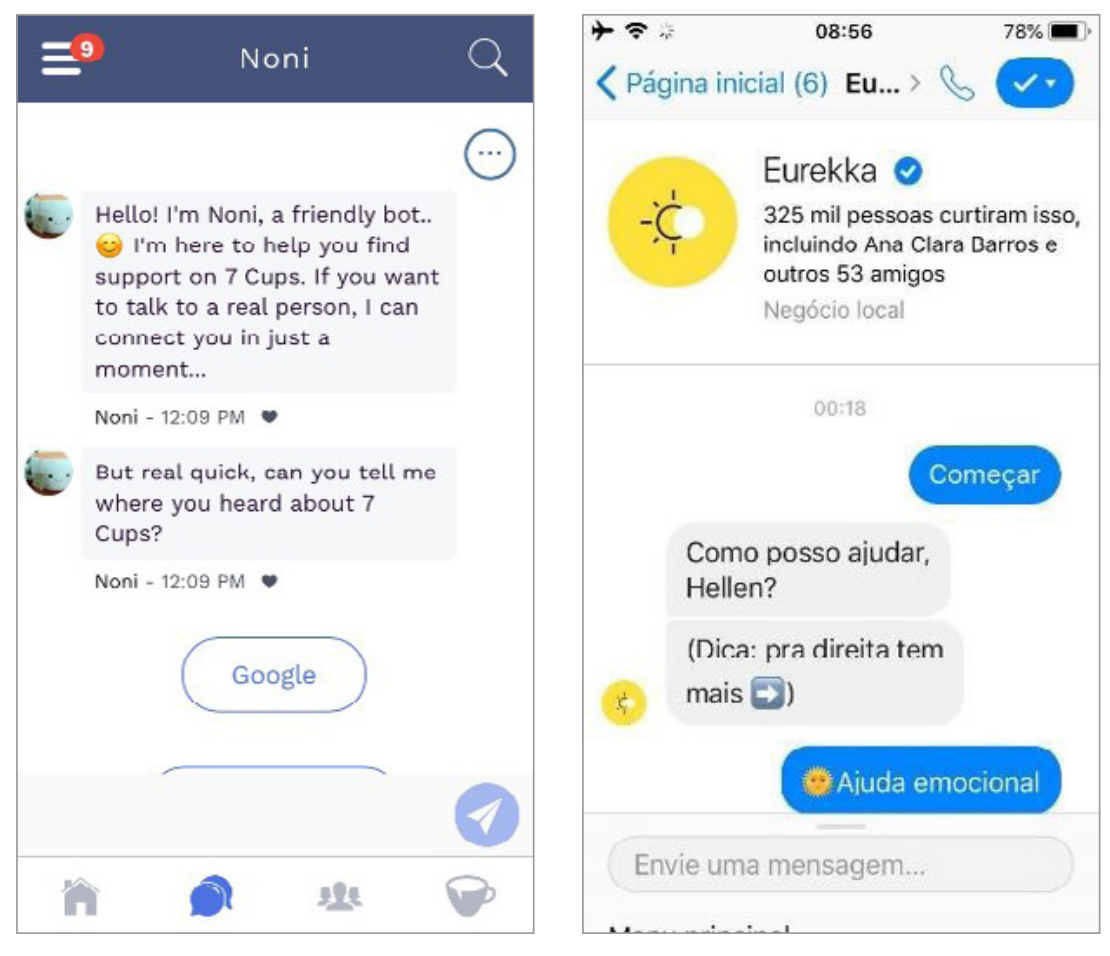

Figura 2: Aplicativos para análise de semelhantes. Fonte: Elaborado pela autora.
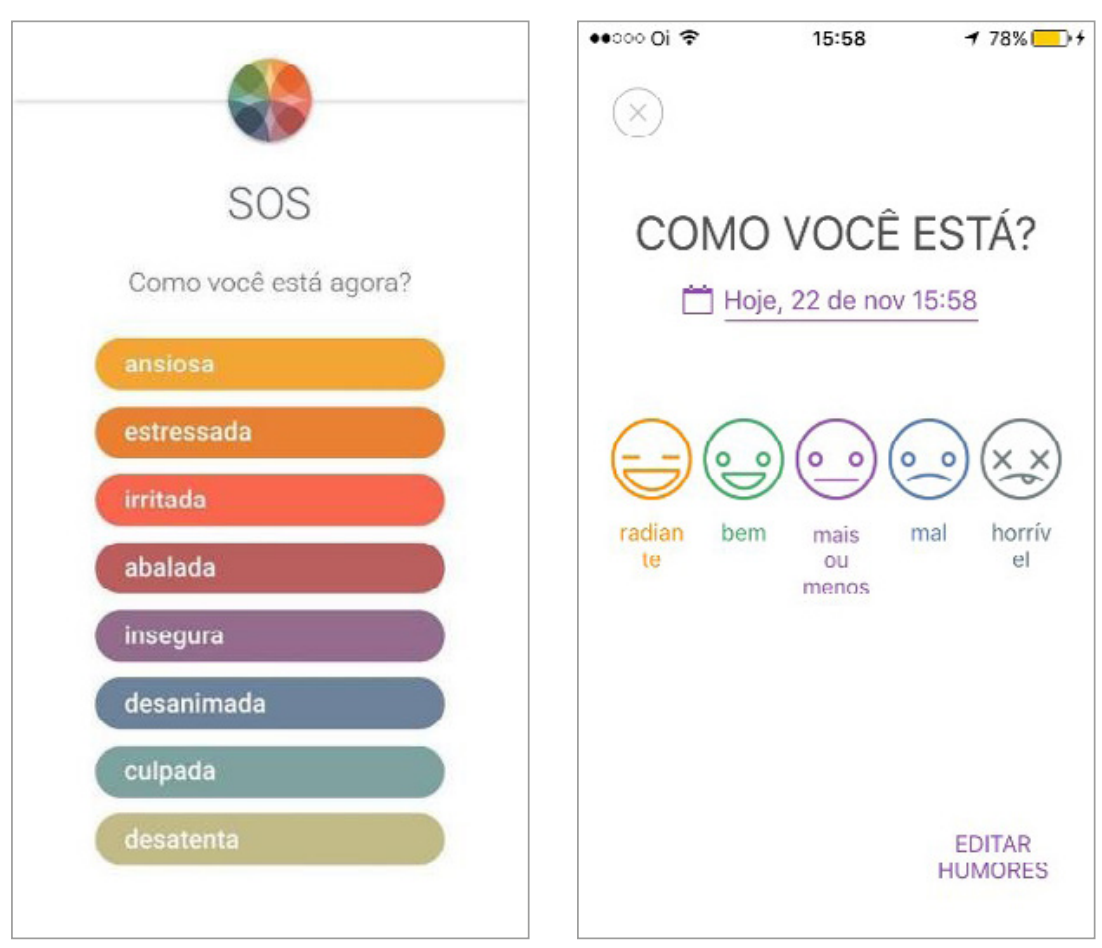


\section{Cenário 1: Busca de apoio emocional através do chat.}

Fernanda terminou um relacionamento recentemente e se sente muito sozinha. Ela não consegue desabafar suficiente com seus amigos e então pesquisa por alternativas online que à possam ajudar. Ela descobre que existe o aplicativo e opta para ir direto para a opção de conversa. Ela se encontra um pouco insegura, mas através da conversa com a inteligência artificial, já se sentiu confortável e aguardou o seu atendimento com o voluntário. Após a conversa, se sentiu melhor, pois se sentiu acolhida do início ao fim, até mesmo com o boot.

\section{PLANO DE ESTRUTURA}

Passando para o plano de estrutura, etapa que segundo Garrett (2011), é quando se desenvolve a estrutura conceitual do projeto, após a definição dos elementos no plano de escopo, elabora-se os fluxogramas onde é traçado os supostos caminhos que o usuário poderá seguir, e as decisões que poderá tomar. Esta etapa dá-se de modo a facilitar a interação do usuário na utilização do aplicativo. Elaborou-se dois fluxogramas onde traçou-se os supostos caminhos que o usuário poderia seguir, e as decisões que o mesmo poderia tomar. $O$ fluxograma 1, foi pensado a partir da decisão do usuário de optar para ir direto para a parte de conversa, e o fluxograma 2 já foi pensado na decisão do usuário de entrar em sua conta para utilizar das demais funcionalidades do aplicativo. Nesse fluxo, teve mais opções para o usuário na tomada de decisões.

\section{PLANO DE ESQUELETO}

O plano de esqueleto, de acordo com Garrett (2011), busca definir como será a funcionalidade do design e sua estrutura de navegação, através de uma interface de comunicação entre o usuário e o aplicativo. É a etapa que elabora-se os protótipos do aplicativo. Realizou-se wireframes de baixa e alta fidelidade. Os de baixa fidelidade, o chat tinha sido pensado primeiramente no mesmo sistema atual do site do Centro de 

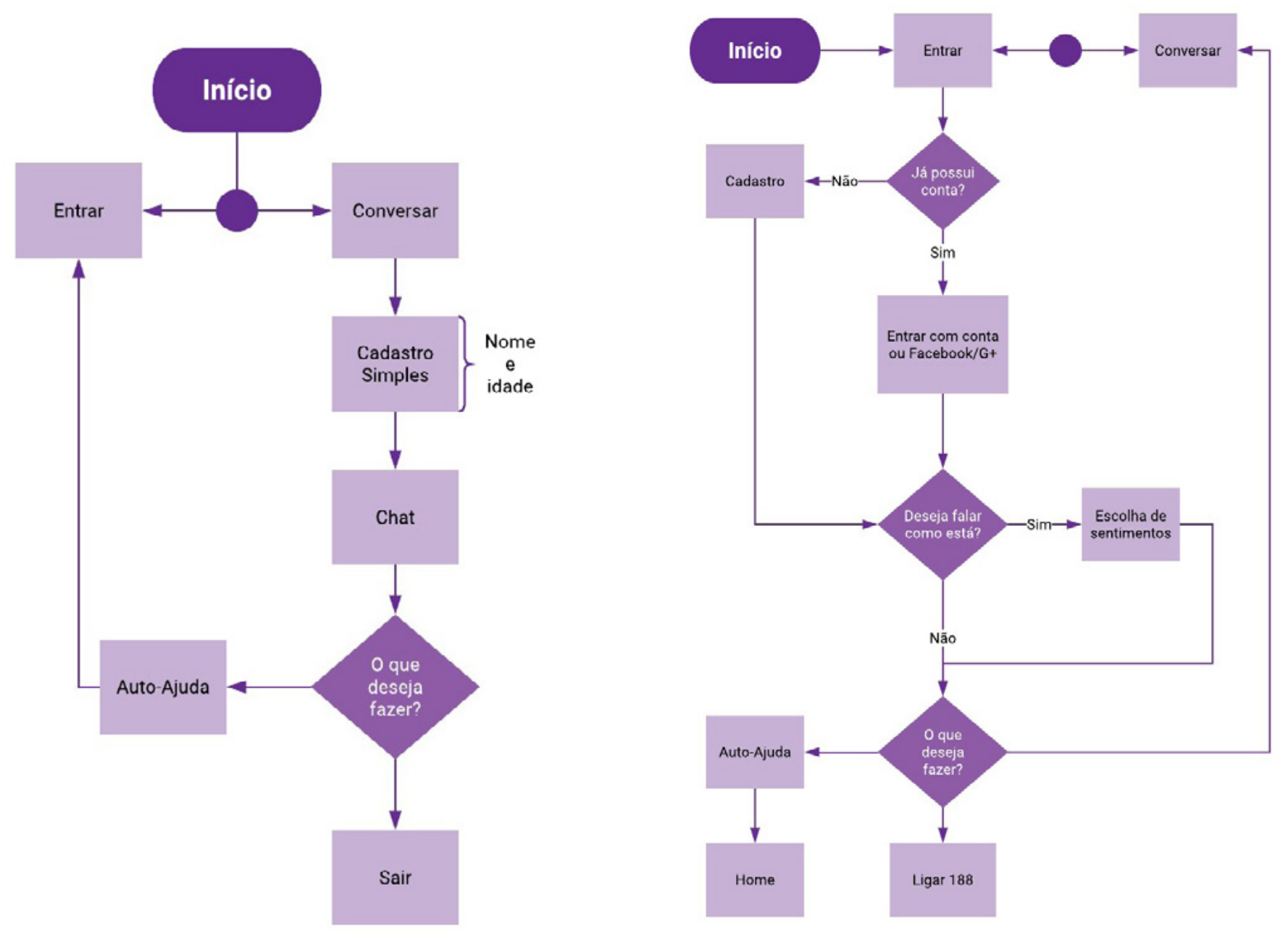

Figura 4: Fluxogramas 1 e 2.

Valorização da vida, onde consta os horários de atendimenFonte: Elaborado pela autora. to e o link para iniciar o chat, mas depois pensou-se no sistema de triagem para conseguir atendimento mais urgente para pessoas que estão em uma situação mais crítica, após a análise da coleta de dados do questionário. A partir do Benchmarking, optou-se pela utilização de um recurso de Inteligência Artificial, que através de suas perguntas e respostas, iria compreender quais são os casos mais urgentes para ser atendidos e quais podem aguardar um pouco mais. Os wireframes de alta fidelidade foram elaborados o mais semelhante possível com a versão final do aplicativo. As modificações a serem feitas depois seriam somente para um aperfeiçoamento, com cores e imagens. Isso se deu pelo fato do software utilizado para elaborar a parte visual do aplicativo, ser a mesma utilizada para a produção dos wireframes, o Adobe XD. 

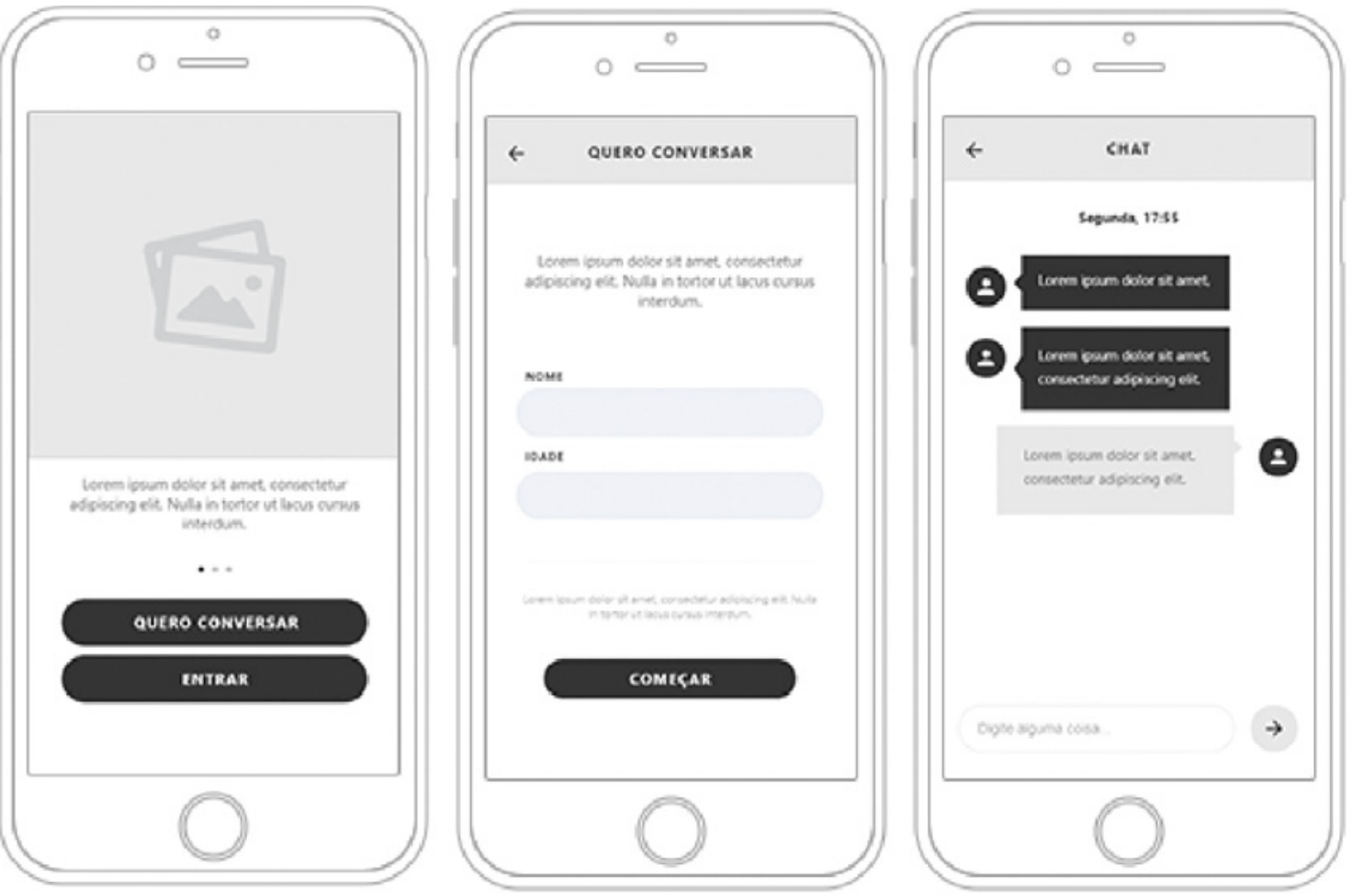

Figura 5: Wireframes de alta fidelidade. Fonte: Elaborado pela autora.

\section{PLANO DE SUPERFÍCIE}

O quinto e último plano, conforme Garrett (2011), o plano de superfície engloba todos os outros planos para refinar e produzir o produto final, o design visual. Primeiramente, foi criado um guia de estilo básico onde mostrou quais as tipografias, as cores, e os ícones que foram utilizados no projeto.

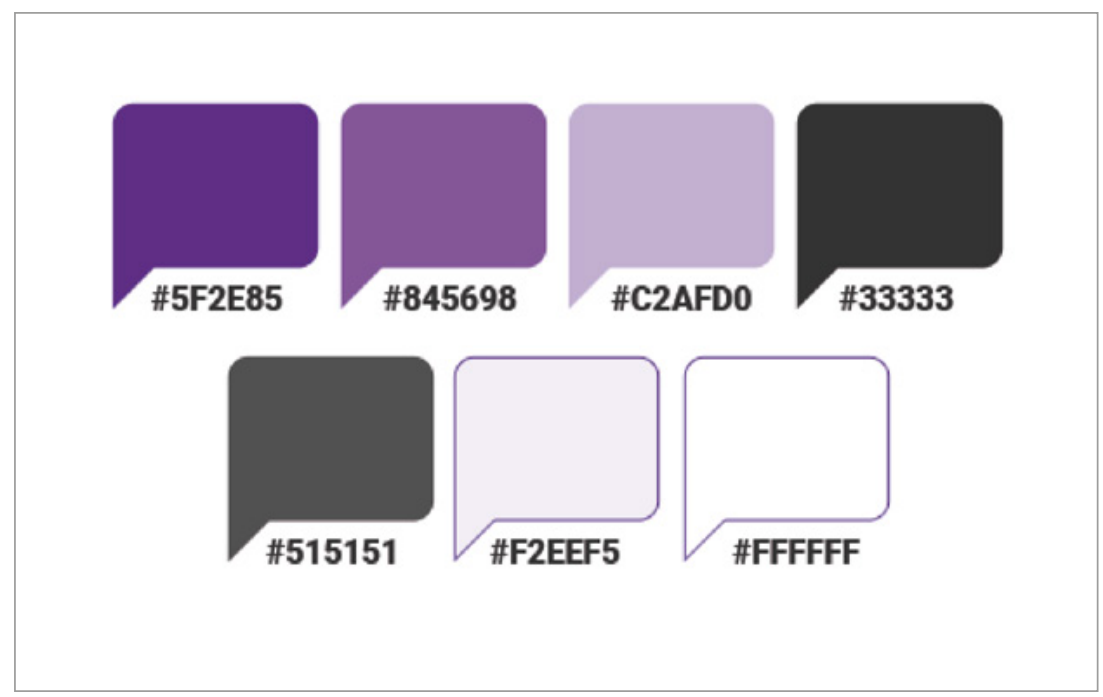

Figura 6 - Guia de estilo básico: Cores. Fonte: Elaborado pela autora. 
Em um segundo momento, apresentou-se todas as telas do aplicativo com a descrição de cada funcionalidade. Optou por descrever as telas desenvolvidas nesta parte ao invés dos wireframes pois haveria uma melhor visualização das telas, já finalizadas.

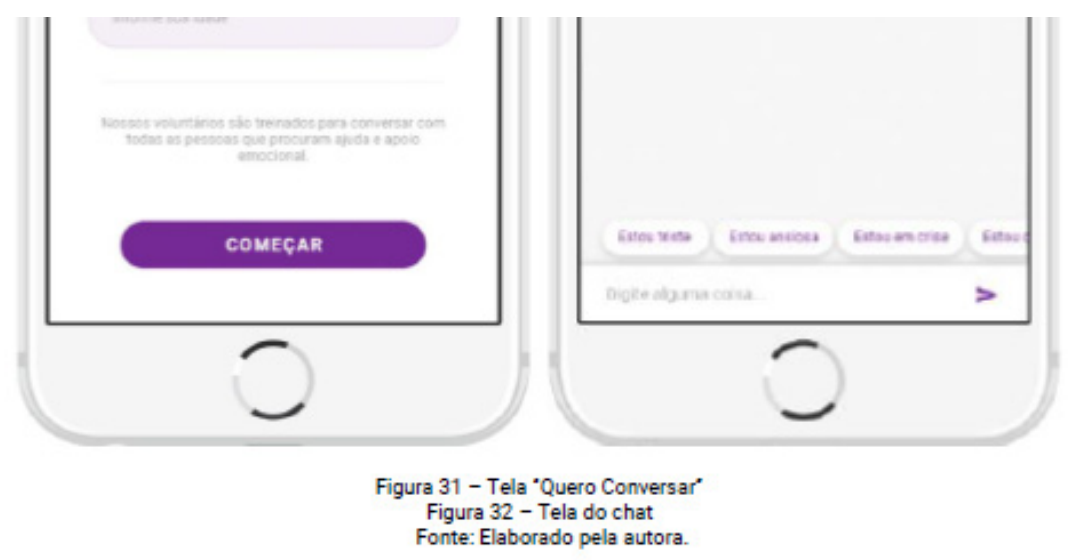

Figura 7 - Telas e as descrições de suas funcionalidades. Fonte: Elaborado pela autora.

O botão "Entrar" leva para a tela de entrar (Fig. 33), que foi pensada em quem já fez o cadastro anteriormente, ou para quem quer se conectar através do Facebook, ou Gmail. Caso o usuário não possua um cadastro e não queira entrar com uma rede social, será feito um cadastro com um formulário simples (Fig. 34), somente com Nome, E-mail, Data de nascimento, e senha.

Figura 8 - Design visual do aplicativo. Fonte: Elaborado pela autora.
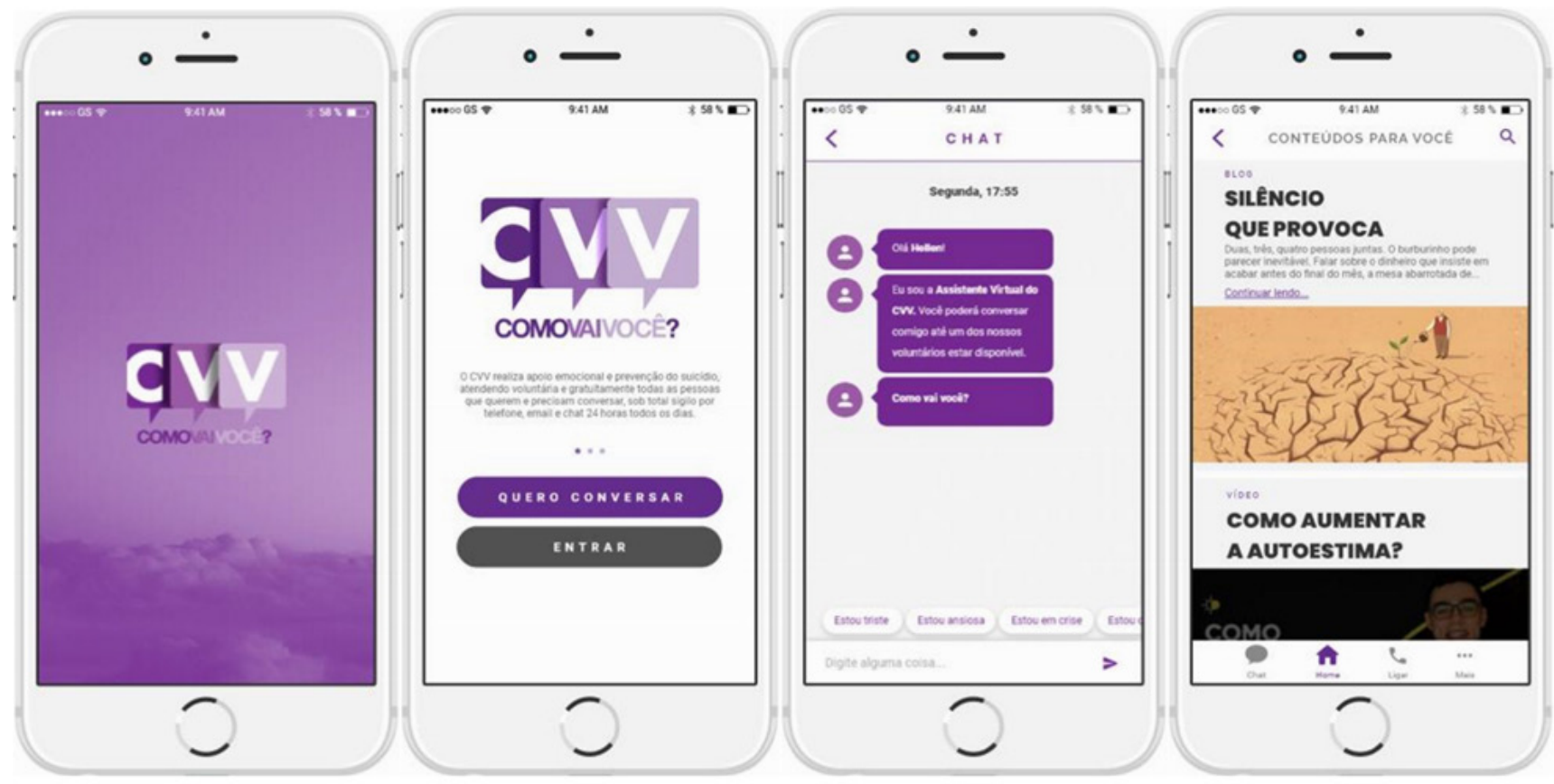


\section{CONCLUSÃo}

A pesquisa teve por intuito a produção de um projeto que pudesse de alguma forma ajudar pessoas. Em um mundo que sofre cada vez mais com a saúde mental, pensar em alternativas que possam auxiliar no cuidado dela, é de tamanha validade. Trazer o Centro de Valorização da Vida para dentro da pesquisa foi consequência desse projeto, visto que a associação vem ajudando há muitos anos pessoas por todo o Brasil, prestando serviço voluntário de apoio emocional a quem quer que esteja precisando.

Compreender mais sobre saúde mental e sobre a depressão, assuntos trazidos no referencial teórico, fez com que se pudesse ter mais empatia pelo assunto e prestar mais atenção no que poderia ou não ser abordado dentro do projeto, visto que a depressão é uma doença delicada, e seu tratamento deve ser feito com acompanhamento de um profissional. Tentou-se enfatizar que a pesquisa não era para projetar um aplicativo de tratamento para a depressão, ou qualquer outra doença relacionada com a saúde mental, e sim um auxílio em uma crise ou uma alternativa temporária enquanto não se consegue o tratamento, visto que o objetivo do CVV é este, e não ajudar no tratamento de transtornos mentais.

Foi importante entender sobre a tecnologia, e observar o quanto o mercado de aplicativos está se expandindo e gerando muitas pesquisas, especialmente nas áreas de saúde, com a mHealth. Trazer a saúde mental através de aplicativos móveis enfatizou o fato de que essa área merece receber uma atenção, e o quanto fora do país já existem diversos estudos relacionados ao tema, com apoio inclusive de instituições como a Organização Mundial de Saúde.

Abordar o Centro de Valorização da Vida, individualmente, fez com que houvesse uma imersão maior na associação, entendendo como ela funciona, e estudando o que se poderia trazer para o projeto. Observar o funcionamento do chat em seu website, fez com que pudessem ser pensadas al- 
ternativas para proporcionar uma experiência melhor para o usuário, como a triagem através da inteligência artificial criada para o aplicativo.

Na parte prática do projeto, todas as etapas trazidas, utilizando da metodologia de Garrett, foram significativas para o desenvolvimento do projeto, desde a parte da estratégia com o questionário aplicado, que ajudou tanto para pensar nas personas, quanto para verificar a validade da pesquisa, até a parte do design visual, que põe em prática todas as etapas anteriores. A análise de semelhantes realizado na etapa de estratégia, fez com que se gerassem ideias de funcionalidades adaptadas para as propostas do CVV, o que era um dos objetivos específicos da pesquisa: gerar novas funcionalidades no aplicativo para além das funcionalidades do website da associação.

Realizar uma pesquisa de Design, que aborda um tema para além da área, reafirma como a mesma é interdisciplinar. Design, não é somente estética. Berman (2002, p. 2) diz que "Os designers podem ser um modelo para outros profissionais por identificar o seu âmbito de influência e, então, abraçar a responsabilidade que acompanha o poder para ajudar a reparar o mundo" tradução nossa.

Com isto, conclui-se que a pesquisa conseguiu atingir os objetivos esperados. Entretanto, devido ao limite de tempo, não conseguiu concretizar outras funcionalidades que foram pensadas ao longo do processo criativo, nem conseguiram ser realizadas todas as telas. Para uma pesquisa futura, isso poderá ser levado em conta, junto com um estudo mais aprofundado sobre aplicativos de saúde, o mHealth. 


\section{REFERÊNCIAS}

CVV, Centro de Valorização da Vida. Disponível em:

<https://www.cvv.org.br>. Acesso em: 30 de nov. 2018

GARRETT, Jesse James. The elements of user

experience: user-centered design for the web and

beyond. 2. ed. New York: AIGA New Riders, 2011.

OPA/OMS. Folha informativa - Depressão.

2018. Disponível em: <https://bit.

ly/2FHaxhK>. Acesso em: 25 nov. 2018.

OPAS/OMS apoia governos no objetivo

de fortalecer e promover a saúde mental

da população, 2016. Disponivel em: <http://

bit.ly/2xw0ANf>. Acesso em: 25 nov 2018.

PRODEST. 0 uso de aplicativos na

sociedade. 2016 Disponível em: <http://bit.

ly/2XfCLDL>. Acesso em: 30 de nov. 2018

SABOIA, Juliana; VARGAS, PL de; VIVA, MA de A. 0

uso dos dispositivos móveis no processo de

ensino e aprendizagem no meio virtual. Revista

Cesuca Virtual: conhecimento sem fronteiras,

v. 1, n. 1, p. 1-13, 2013. Disponível em: <https://

bit.ly/2Ry3SYt> Acesso em: 30 de nov. 2018 